\title{
Review
}

\section{Anti-inflammatory potential of edible ornamental flowers grown in containers due to high anthocyanin content}

\author{
Grzegorz P. Łysiak
}

Department of Ornamental Plants, Dendrology and Pomology, Poznan University of Life Science, Poznan University of Life Sciences, ul. Dąbrowskiego 159, 60-594 Poznań, Poland, glysiak@up.poznan.pl

\begin{abstract}
Flowers have always accompanied people thanks to their manifold aesthetic properties. Some species have also become a component of human diet. Recent years have seen an increased interest in edible flowers and, consequently, research has been undertaken to determine their chemical composition. Dyes abundantly contained in flowers, whose role is to attract pollinating animals, are recognized substances with health promoting properties. Anthocyanins are a group of dyes that is very common in petals and other parts of flowers. Studies carried out in the twentieth and twenty-first century have found very strong antioxidant and anti-inflammatory properties of anthocyanins. Therefore, flowers used by humans for centuries to decorate their surroundings may become an easily available source of nutrients and health-promoting substances. This paper discusses the health-promoting properties of anthocyanins and collects literature on anthocyanin content in edible flowers commonly grown on balconies, terraces and roofs.
\end{abstract}

Keywords: agroecosystem, urban ecology, perennial and annual flowers, anti-inflammatory, antioxidant properties, biological activity

\section{Introduction}

Increased lifespan and a better quality of life have dramatically improved life expectancy of the world population. This tendency is especially visible in Western countries, but at the same time, the high availability of hypercaloric food and the increase in consumption of highly processed foods have led to the massive occurrence of chronic non-communicable diseases - mainly cardiovascular, metabolic and neurodegenerative diseases - in those countries [1]. In 2016, the World Health Organization (WHO) estimated that approximately 650 million adults were obese [2]. For these reasons, particular emphasis should be placed on increasing the consumption of fresh food containing bioactive compounds, as these substances provide health protection when interacting at many levels. Among fresh foods, especially plant-based foods contain a lot of bioactive compounds, such as polyphenolic compounds, which modulate processes occurring in the human body and have antioxidant, anti-inflammatory, anticancer, and neuroprotective effects, and can modulate glucose levels [3].

The growing demand for new nutraceutical plant food has sparked interest in edible flowers. Various flower pigments, formed in the process of evolution to attract pollinator organisms, have been shown to have high antioxidant activity, which can be a remedy for diseases of civilization [4]. Anthocyanins play an important role in the attraction strategy involving the use of colour, but their strong antioxidant potential also makes flowers an important resource, the use of which should be increased in cultivation and nutrition [5]. Flowers commonly grown by humans and thus often present in the human environment,(for example, planted every year in containers on balconies, terraces and roofs), due 
to the high content of biologically active substances, could become something of a "home pharmacy" helping to fight modern diseases.

\section{Chemistry and Biochemistry of Anthocyanins}

The word 'anthocyanin' derives from two Greek words: anthos, which means flowers, and kyanos, which means dark blue [6].

Anthocyanins are secondary metabolites in land plants that contribute to the colour of leaves and flowers [7]. These pigments are primary blue, red and purple. They are synthesized via the flavonoid pathway, which is part of the general phenylpropanoid pathway [8]. The entry to the biosynthesis of phenylpropanoids is the shikimate pathway. In this pathway plants biosynthesise in three steps hydroxycinnamic acids and their derivatives, which are the precursors for a large variety of aromatic metabolites [9]. The next step before the synthesis of anthocyjanidins is the conversion of a chorismic acid to phenylalanine by the enzyme phenylalanine ammonia-lyase [10] from which cinamic acid is formed. The conversion of cinamic acid to anthocyanins requires a series of reactions: the first reaction is catalyzed by cinnamate 4-hydroxylase to form a coumaric acid and by 4-hydroxy-cynnamoyl CoA ligase to create 4-Coumaroyl CoA, which is a direct precursor to kaempferol. After four steps of enzymatic reaction from 4-Coumaroyl CoA the leucoanthocyanidins are formed [11]. By the catalysis of anthocyanin synthase (ANS), the colorless leucoanthocyanidins (flavan-3,4-diols) are oxidized to the coloured anthocyanidins [9]. Flavan-3,4-diols, also known as leucoanthocyanidins, are not particularly prevalent in the plant kingdom, instead being themselves precursors of flavan-3-ols (catechins), anthocyanidins, and condensed tannins (proanthocyanidins) Anthocyjanidins are unstable under physiological conditions so they are immediately glycosylated in the 3-OH positions by UDP-glucose-flavonoid 3-O-glucosyltransferase (UFGT) to form the more hydrophilic and stable anthocyanins [12].

It has been experimentally demonstrated that all anthocyanin pigments are derived from one of three aglycones (pelargonidin, cyanidin and delphinidin). The differences in the colour of anthocyanins result from the pattern of hydroxylation and methylation, and the amount and type of sugars [13]. Anthocyanins display different colours (red, blue and purple) depending on their accumulation and chlorophyll complementary light absorbance. At low $\mathrm{pH}$ values, anthocyanins are present as flavylium cations (oxonium charged oxygen), while under neutral conditions uncharged quinones are formed [14]. At $\mathrm{pH}$ around 2.0-3.5 anthocyanins have a pink-coral colour, while at 5.5-6.5 they are blue to purple [13]. The chromophore of conjugated double bonds carrying a positive charge on the heterocyclic oxygen ring is responsible for the intense red-orange to blueviolet colour produced by anthocyanins under acidic conditions [15].

There were 635 identified anthocyanins in 2010 [16]. Anthocyanins are present in nature mainly in the form of heterosides. The aglycon form of anthocyanins are called anthocyanidin. The basic structure of anthocyanins is composed of flavylium cation (C6-C3-C6), which could be linked to different sugars or hydroxyl or methoxyl groups [17]. The most abundant anthocyanins are delphinidin, cyanidin, petunidin, peonidin, malvidin, and pelargonidin. Glucose is the most common sugar attached to anthocyanins, but also rhamnose, xylose, galactose, arabinose, and rutinose have been reported to be linked to these compounds [6]. Depending on the number of attached sugars, anthocyanins can be mono-, di-, or tri-glycosides [17]. The presence of sugars gives more stability and water solubility than their corresponding glycosides [9]. Glycosylation primarily at the C-3 residue results in reduced maximum wavelength absorption [18].

Sugar residues may be further acylated with cinnamic acids, such as p-coumaric, ferulic, and sinapic acid, as well as aliphatic acids, such as acetic, malonic, and oxalic acid [19]. 


\section{Antioxidant and anti-inflammatory activity of anthocyanins}

\subsection{Anioxidant activity}

The antioxidant potential of anthocyanins depends on the ring orientation (which determines the ease with which a hydrogen atom from a hydroxyl group can be donated to a free radical), the ability of the anthocyanin to support an unpaired electron [20], the number of free hydroxyls around the pyrone ring and their positions, and the presence of other types of radicals in the main structure [21]. The protection of these pigments against oxidation process depends on their structures. Principally, the antioxidant activity of anthocyanins is associated with the number of free hydroxyls around the pyrone ring. Higher antioxidant activity is due to the number of hydroxyls [20].

Individual anthocyanins differ in their ability to remove highly active radicals depending on the radical. For instance, pelargonidin is the most efficient against the hydroxyl radical, whereas delphinidine is the most active against the superoxide anion [22]. Free radical damage contributes to the aetiology of many chronic diseases and thus antioxidants may have beneficial effects on human health at different levels [23]. Improving the diet through the consumption of products containing natural antioxidants is one of the best strategies to create a balance between the activity of free radicals and the antioxidant system in human body [24].

The antioxidant capacity of consumed products can be measured using chemical, in vitro methods generally performed on extracts. The literature mentions nearly 20 methods $[9,11,13]$, but in general, if there are many methods, none of them is perfect. In addition, we must remember that the indicators give us a picture of the potential of the product, but they will not answer the question of how many substances will be absorbed and what impact they will have on the body. The most popular methods of measuring antioxidant potential are based on the ability to bind free radicals (DDPH, ABTS), to reduce cupric or ferric ions (FRAP, CUPRAC), to protect a target molecule exposed to a free radical source (ORAC, TRAP) and to inhibit the oxidation of low density lipoprotein (LDL) [25]. Antioxidant capacity is a function of the content and types of phytochemicals that are present in fresh tissues. However, individual groups of compounds may differ considerably in terms of antioxidant properties. Many studies indicate that phenols and flavonoids contribute more strongly to antioxidant capacity than ascorbic acid, vitamins, carotenoids, and other compounds [26]. Anthocyanin molecules, due to their structure, stand out from flavonoids as a group of compounds exhibiting very high antioxidant capacity [27]. Still, some research suggests that the bioavailability of anthocyanins is lower than that of other flavonoids. Anthocyanins were initially perceived as poorly absorbed and metabolized compounds, which cast doubt on whether they could have a biological effect in humans. They were found only in the plasma in their intact form (glycosylated). However, most of those studies were based on plasma and urine analysis for anthocyanin metabolites derived from glucuronidation and sulphation metabolism. More recent studies increasingly allow to identify metabolites of anthocyanins at higher concentrations than the parent compounds [28]. According to some research, anthocyanins may be metabolized by intestinal microflora producing a group of new products that have not yet been identified, not to mention quantified. In addition, recent studies indicate that anthocyanins are rapidly absorbed, with maximum plasma concentration (Cmax) of between 45 min to $4 \mathrm{~h}$ after ingestion of a meal containing anthocyanins, depending on the conditions of the trial. When anthocyanins were ingested alone and after a night, Cmax was reached after only $1 \mathrm{~h} \mathrm{[29],} \mathrm{but} \mathrm{if} \mathrm{they} \mathrm{were} \mathrm{consumed} \mathrm{together} \mathrm{with}$ other food, the absorption decreased; especially if food contained fat, Cmax was reached only after 4 hours [30]. The structure of anthocyanins affects their absorption by the human body. It has been shown that 3-monoglucosides of anthocyanidins are less bioa- 
vailable than their corresponding rutinosides [31]. Also, the absorption differences between malvidin and petunidin may be due to the fact that a large number of hydroxyl groups in the molecule decreases its bioavailability. However, it should be remembered that the absorption capacity will also depend on the amount of anthocyanins and the presence of other compounds. It was found out that the ingestion of anthocyanins together with sugar slowed down their absorption while the consumption of anthocyanins together with alcohol significantly accelerated their intake [32].

\subsection{Ani-inflamtory activity and protection against chronic diseases}

The health benefits of anthocyanins have been studied in a variety of models, ranging from human clinical trials to animal and cell culture screening to epidemiological studies [17]. The human body is in constant contact with external factors that can cause various types of damage, irritation or allergies [9] often leading to inflammation. Inflammation is a complex set of relationships between soluble compounds that can arise in any tissue in defensive response to traumatic, infectious, post-ischemic, toxic, or autoimmune injury. It is typically induced by microbial infections, but can also be triggered by tissue injury or trauma that occurs without the intervention of pathogens (sterile inflammation). The inflammation process usually leads to recovery from infection and healing [33].

Adaptive innate immune response induces rapid activity following infection. A wide range of molecular patterns are detected, commonly found in pathogens but foreign to mammals. They are called pathogen-related molecules patterns (PAMP) [34]. Such particles are lipopolysaccharides, surface phosphatidylserine, and aldehyde derivatized proteins as well modified forms of the classic risk factor for atherosclerosis, oxidatively modified low-density lipoprotein (LDL) or glycation [35]. The cellular response may be lysosomal endocytosis, degradation bound ligands. Involvement in the process of Toll-like receptors causes the activation of the nuclear factor kappa B (NF- $\kappa \mathrm{B})$, and protein kinase. It can induce increased phagocytosis, production of reactive oxygen and release of cytokines, autacoids and lipids coordinating and strengthening local inflammation answer [36], [37]. Recent research demonstrate that metabolites of anthocyanins can reduce the activation of NF- $\kappa \mathrm{B}$ [38]. Protein kinases, cellular stress kinases, extracellular signal-regulated kinases, mitogen-activated protein kinases (AMPK) are another molecular target of anthocyanins and have been shown to be sensitive to anthocyanin treatment reducing downstream cellular signaling networks associated with serious diseases, such as chronic inflammation [17]. AMPK-activated protein kinase involved in cellular energy (glucose) metabolism caused diabetes appears to be one of the main targets of anthocyanins [39]. AMPK is an important regulator of energy homeostasis and is a molecular target of drugs used for the treatment of obesity and other metabolic diseases [40]. Another target of anthocyanins are thrombin receptor activating peptide and vascular endothelial growth factor, which are responsible for angiogenesis, cancer, and atherosclerotic risk [41].

The biological activity of isolated anthocyanins and anthocyanidins, or foods rich in anthocyanins, can be manifested in: prevention of cardiovascular disease [42], influence on cholesterol distribution, protection of endothelial cells from CD40-induced proinflammatory signaling [43], anticancer, antitumor and antimutagenic activity [44], beneficial effects in diabetes [45], protective effect against oxidative liver damage [46], protective effect on gastric inflammation and damage [47], antimicrobial and antiviral activity [48, 49], slowing down neuronal and behavioural aging [50] and protection from some neurodegenerative diseases such as Alzheimer's disease [51]. Anthocyanins and anthocyanidins also effectively induce insulin secretion when tested in pancreatic cell lines 
[11]. The effectiveness of insulin secretion depends on the number of hydroxyl groups in the B-ring of their structures [45].

Cyanidin $\left(\mathrm{C}_{15} \mathrm{H}_{11} \mathrm{O}_{6}\right)$ and its derivatives are the most common anthocyanins in flowers (Table 1). The study carried out by Samarpita and Rasool [52] suggests that cyanidin is a potent inhibitor of Interleukin (IL)-17A signaling associated pathogenesis of rheumatoid arthritis, the most common autoimmune arthropathy. Cyanidin not only effectively blocks interleukin 17A/p38 but also suppresses osteoclastogenesis. This study suggests that cyanidin has great potential as a small molecule drug to be used in clinics to treat rheumatoid arthritis patients [52]. Moreover, there is evidence that cyanidin as well as delphinidin have the chemo preventive effect against skin cancer [53].

The effect of anthocyanins on microbial pathogens has not been studied in depth up to now. However, the results obtained so far are very promising.

\section{Factors influencing anthocyanin content in ornamental plants}

Anthocyanin accumulation is strongly regulated by plant development and genotype, and by environmental factors [54]. One of the goals of ornamental plant breeding is to broaden the colour palette of different species by adding missing colours. For example, the best-selling cut flowers so far, namely, rose, chrysanthemum, carnation and lily, include no blue cultivars in their palette, while petunias are not red / orange [55]. Purple flowers in rose and carnation were obtained by changing the decoration pattern on the basic skeleton of anthocyanins, i.e. increasing the accumulation of delphinidin [56].

Temperature has a big impact on anthocyanin accumulations. Strong temperature variations between day time and night time favour the accumulation of soluble solids, and more soluble solids enhance the accumulation of anthocyanin [57]. However, too low temperatures slow down physiological processes and can thus also limit anthocyanin production. The plant hormone abscisic acid (ABA) has been suggested to play an important role in anthocyanin accumulation. ABA treatment increases anthocyanin content in grape skin and induces the expression of anthocyanin-biosynthesis genes [58]. Studies on the effect of altitude on anthocyanin accumulation in blueberry fruit found out that plants growing at a lower altitude accumulated more anthocyanins [54].

Fertilization also affects anthocyanin accumulations. Pre-harvest calcium treatment was shown to upregulate the expression of anthocyanin structural genes and to increase the total phenolic and anthocyanin content [59]. The accumulation of anthocyanins in the plant is also promoted by better availability of phosphorus in soil [60] and by the application of melatonin (N-acetyl-5-methoxytryptamine). It is explained that melatonin is involved in secondary metabolism, where it induces anthocyanin and flavonoid biosynthesis [61]. The plant's growing location also plays a role because it has been shown that ultraviolet B emitted by the sun (wave length: $280-315 \mathrm{~nm}$,) promotes anthocyanin synthesis. This is the part of the radiation which is only partially absorbed by the ozone layer and therefore exposure to direct sunlight stimulates the formation of anthocyanins [62].

The production of anthocyanins in ornamental plant species is also enhanced by a change in the activity of flavonoid enzymes by gene modification. This method to increase the content of anthocyanin pigments was applied to petunias and torenias [63,64]. At the genetic level, gibberellins, which are regulators of growth and development, can also interact. It was found that during the development of petunia flowers gibberellin induced the expression of some genes such as those of chalcone synthase, chalcone isomerase, anthocyanidin synthase, and dihydroflavonol 4-reductase, which are responsible collectively for corolla pigmentation [65], [66]. 


\section{Anthocyanin content of domestic grown edible flowers}

Table 1. Anthocyanin content in edible flowers grown in containers

\begin{tabular}{|c|c|c|c|c|c|c|c|c|c|}
\hline \multirow[b]{2}{*}{ Flower species } & \multicolumn{8}{|c|}{ Anthocyanins* } & \multirow[b]{2}{*}{ Source } \\
\hline & 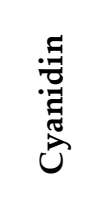 & 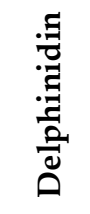 & 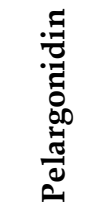 & 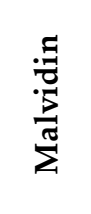 & 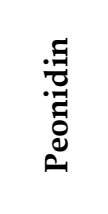 & 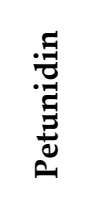 & 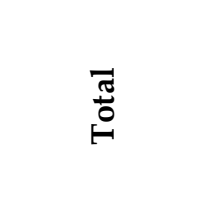 & $\begin{array}{c}\text { ORAC/FRAP }^{1} \\
(\mathrm{TE} / \mathbf{1 0 0 g})^{\mathrm{A}} \\
\left(\mathrm{mmol} \mathrm{FeSO}{ }^{4}\right. \\
/ 100 \mathrm{~g})^{\mathrm{B}}\end{array}$ & \\
\hline $\begin{array}{c}\text { Ageratum } \\
\text { houstonianum }\end{array}$ & & & & & & & $27.85^{8}$ & $2.99 \mathrm{~A}, 8$ & {$[5]$} \\
\hline $\begin{array}{l}\text { Argyranthemum } \\
\text { houstonianum }\end{array}$ & & & & & & & $2.99^{8}$ & $27.85^{\text {в }}$ & {$[5]$} \\
\hline Begonia sp. & $\mathrm{p}^{\mathrm{D}}$ & & & 759.1 & & & $5.09^{8}$ & $21.18^{\text {в }}$ & [5], [67], [68] \\
\hline Bellis perennis & $\mathrm{p}^{\mathrm{D}}$ & & & $\mathrm{p}^{\mathrm{D}}$ & & & no & data & [69] \\
\hline Campanula sp. & & $\mathrm{p}^{\mathrm{D}}$ & $\mathrm{p}^{\mathrm{D}}$ & & & & & & {$[70],[71]$} \\
\hline Calendula officinalis & & & & & & & $22.1^{7}$ & $\begin{array}{l}3.68^{\text {А }} \\
58.05^{\text {в }}\end{array}$ & {$[5],[72],[73]$} \\
\hline Dahlia sp. & 121.2 & & 2.65 & & & & $17.6-257.5^{7,9}$ & $17-24^{5,9}$ & {$[74],[75]$} \\
\hline Dianthus & 52.4 & $\mathrm{p}^{\mathrm{D}}$ & $\mathrm{p}^{\mathrm{D}}$ & & & & $0.73-13.35^{8,9}$ & $5.4-10.2^{\mathrm{A}, 9}$ & {$[5],[76],[77]$} \\
\hline Dendranthema & $\mathrm{p}^{\mathrm{D}}$ & $\mathrm{p}^{\mathrm{D}}$ & $\mathrm{p}^{\mathrm{D}}$ & & & & & $168-182^{\text {в }}$ & [69], [78], [79] \\
\hline Fhaseolus cocineus & & & & & & & & & no data \\
\hline Fuchsia sp. & $\mathrm{p}^{\mathrm{D}}$ & & & & $\mathrm{p}^{\mathrm{D}}$ & & $7.58^{8,9}$ & $47.52^{\text {в }}$ & {$[5],[80]$} \\
\hline Glechoma hederacea & $\mathrm{p}^{\mathrm{D}}$ & $\mathrm{p}^{\mathrm{D}}$ & & & & & no & data & {$[81]$} \\
\hline Heliotropium oxalis & & & & & & & & & no data \\
\hline Helichrysum & & & & & & & & $419.8^{\text {в }}$ & {$[82]$} \\
\hline Hemerocallis & & & & & & & & $21.0-29.0^{\mathrm{A}}$ & {$[83]$} \\
\hline Hibiscus sp. & 2080 & 5650 & & & & & $155-206^{8}$ & $83.1^{5}$ & $\begin{array}{c}\text { [84], [85], [86], } \\
{[87]} \\
\end{array}$ \\
\hline Impatiens & & & $\mathrm{p}^{\mathrm{D}}$ & & $\mathrm{p}^{\mathrm{D}}$ & & no & data & {$[88]$} \\
\hline Lavandula & & & & & & & & $277.60^{\text {в }}$ & {$[81]$} \\
\hline Lobelia & & & & & & & & & no data \\
\hline Lobularia maritima & $\mathrm{p}^{\mathrm{D}}$ & $\mathrm{p}^{\mathrm{D}}$ & & & & & no & data & {$[89],[90]$} \\
\hline Myosotis & & & & & & & & $171.60 \mathrm{~A}$ & {$[81]$} \\
\hline Pelargonium spp. & $\mathrm{p}^{\mathrm{D}}$ & $\mathrm{p}^{\mathrm{D}}$ & $\mathrm{p}^{\mathrm{D}}$ & $\mathrm{p}^{\mathrm{D}}$ & $\mathrm{p}^{\mathrm{D}}$ & $\mathrm{p}^{\mathrm{D}}$ & $12.52^{8}$ & $34.78^{\mathrm{B}, 9}$ & [5], [91] \\
\hline Petunia & $53.2^{2}$ & $31.3^{2}$ & $49.0^{4}$ & $2.6^{4}$ & $87.1^{3}$ & $8.5^{3}$ & $28-114^{9}$ & $5.4-10.22$ в,9 & [5], [92], [93] \\
\hline Rosa & 357.0 & & 31.2 & & $\begin{array}{l}140.4^{-} \\
153.1^{10} \\
\end{array}$ & & $2.3-7.0^{8}$ & $71.4-397.4^{\mathrm{A}, 9}$ & $\begin{array}{c}\text { [94], [95], [71], } \\
{[96]} \\
\end{array}$ \\
\hline Tagetes erecta & 33 & & 3.8 & & & & $0.75^{8}$ & $\begin{array}{c}70.42^{\mathrm{B}} \\
266.11^{\mathrm{A}} \\
\end{array}$ & [5], [97] \\
\hline
\end{tabular}




\begin{tabular}{|c|c|c|c|c|c|c|c|c|c|}
\hline Tagetes patula & $0.25^{6,9}$ & $\mathrm{p}^{\mathrm{D}}$ & & $\mathrm{p}^{\mathrm{D}}$ & & $\mathrm{p}^{\mathrm{D}}$ & & $0.076-0.433^{6,9}$ & [73], [98] \\
\hline Torenia sp. & $0.9-41.0^{9}$ & 210.96 & & $4.2-134.9^{9}$ & & & $5.0-152.7^{9}$ & $8907.50^{\mathrm{A}}$ & $\begin{array}{c}\text { [68], [99], } \\
\text { [100], }\end{array}$ \\
\hline Tropaeolum majus & $4.77^{8}$ & $32.208^{8}$ & $32.06^{8}$ & - & - & - & $68.12^{8}$ & $7111-18719$ A, 9 & [101] \\
\hline Tulipa sp. & $\mathrm{p}^{\mathrm{D}}$ & $\mathrm{p}^{\mathrm{D}}$ & $\mathrm{p}^{\mathrm{D}}$ & & & & $3.8-4.0^{9}$ & $29.23^{B, 11}$ & $\begin{array}{l}{[102][103],} \\
{[104],[105]}\end{array}$ \\
\hline Viola cornuta & $70.0^{7}$ & $1350^{7}$ & & & & & & $25.0^{\text {в }}$ & [73], [106] \\
\hline Viola witrockiana & $1.9-16.7^{9}$ & $8.6-21.8^{9}$ & & $8.8-14.2^{9}$ & & $1.2-15.9$ & $0.35-13.6^{9}$ & $0.82-36.55^{\mathrm{B}, 9}$ & [5], [107], [108] \\
\hline
\end{tabular}

* the content of individual anthocyanins is given together with their derivatives like glycosides, rutinosides and others, as a sum of identified anthocyanins

${ }^{1}$ Oxygen radical absorbance capacity

D Presence identified but no quantitative data available

2 Average value for 8 cultivars

${ }^{3}$ Average value for 3 cultivars

${ }^{4}$ Average value for 4 cultivars

${ }^{5}$ Antioxidant capacity was measured using 2, 2- diphenyl-1-picrylhydrazyl (DDPH), data expressed as percent inhibition of DPPH

${ }^{6} \mathrm{~g} / 100 \mathrm{~g} \mathrm{FW}$, there is sum of three cyanidins, the share of cyanidin-3- galloylsophoroside is $60-90 \%$

${ }^{7}$ Equivalent of pelargonidin mg per gram of sample DW

${ }^{8}$ Equivalent of mg cy-3-glu/100 g FW and DW for Hibiscus, Petunia, Rosa, Tropaeolum,

${ }_{9}$ Depends on the cultivar

${ }^{10}$ Depends on the season

11 Wild species Tulipa humilis

The content of anthocyanins has not been tested yet in many edible flower species (Table 1). A number of studies were carried out in the 1980s and 1990s to find individual anthocyanins, sometimes also their derivatives [80, 81, 88, 91]; however, there were no technical possibilities to allow the measurement of anthocyanin content. The highest total amount of anthocyanins was fond in petals of perennial hibiscus; annual flowers with the highest anthocyanin concentration were Dahlia sp., Petunia sp. and Tropaeolum majus [75, $92,93]$. So far, it has been found that all species grown on balconies, terraces or roofs of houses, whose flowers are edible, show high antioxidant capacity. [5]. The content of anthocyanins strictly depends on the cultivar $[91,93,109]$ and the development phase of flowers $[109,110]$. Annual flowers grown in the human environment can be a very important source of anthocyanins [71,77, 98], but also perennial flowers grown in larger pots, such as roses or hibiscus, are known to be an excellent source of polyphenols [33, 87, $95,96]$.

\section{Pharmacy in the neighbourhood (balconies, roofs, terraces)}

We live in a world where only a small percentage of land remains relatively undisturbed. The urban landscape is not only to be functional, but also to actively provide cultural experiences and to create a harmonious structure [111]. Nowadays, terraces or residential courtyards in an urban or agricultural environment take up the role of kitchen gardens, contributing not only to the development of urban agriculture, but also to increasing the availability of health-promoting substances. People often turn balconies, roof terraces, or patios into an attractive space to dine and entertain with stylish lighting and furnishing ideas. At such "home plots" the cultivation of ornamental plants occupies an important place [112]. In addition to aesthetic advantages, such a location can also be a source of edible flowers, which, in addition to stunning delicacy, can perform their health-promoting functions. 
The ability of anthocyanins to induce antioxidant and detoxifying enzymes has potential implications for cancer prevention and for modifying cellular oxidant status [17]. Health and therapeutic effects of anthocyanins are related to their chemical and biochemical properties, which are partially explained by their antioxidant activities. However, anthocyanins are relatively unstable and easily oxidized. They are sensitive to many factors, like temperature, UV radiation, the presence of sulfur dioxide, some ions ascorbic acid [64, 113]. Therefore, easy access to edible flowers containing anthocyanins can support the bioavailability of these compounds to consumers.

The concentration of anthocyanins in fresh fruits and vegetables can significantly drop even during only several days of storage in a cold store, as demonstrated by a study on the level of pelargonidin 3-glucoside and cyanidin 3-glucoside, the two anthocyanidin glycosides responsible for the colour of strawberries. Similar conclusions can be drawn based on various other studies, such as that on storing 'Jonagold' apples for 120 days, in which the amount of anthocyanins decreased during storage from $158 \mathrm{mg} / 100 \mathrm{~g}$ to 119 and $103 \mathrm{mg} / 100 \mathrm{~g}$ [115]. Growing flowers in the neighborhood and harvesting them for direct consumption just before a meal makes it possible to avoid the degradation of these beneficial compounds.

\section{Conclusion}

The existing literature indicates that many ornamental plants growing in the immediate vicinity of humans can be an abundant source of anthocyanins. Many researchers focus on widely recognized products rich in anthocyanins, such as wine or berry plants. However, more studies are needed to determine both the quantitative and quantitative anthocyanin content of edible flowers. Biotechnology offers promising methods to increase anthocyanin levels in edible flowers, whereas more widespread cultivation of flowers in containers on balconies, terraces and roofs makes it easier for humans to include them in daily diet. The literature on the subject provides sufficient evidence showing that edible flowers rich in anthocyanins may have a protective effect on human health, especially by preventing the occurrence of cancer and neurodegenerative and cardiovascular diseases.

Funding: The publication was co-financed within the framework of the "Regional Initiative Excellence" programme implemented at the initiative of the Polish Ministry of Science and Higher Education in 2019-2022 (No. 005/RID/2018/19)", financing amount: PLN 12,000,000.

Institutional Review Board Statement: "Not applicable"

Informed Consent Statement: "Not applicable"

Data Availability Statement: “Not applicable".

Conflicts of Interest: "The author declare no conflict of interest."

\section{References}

1. Rauber, F.; da Costa Louzada, M.L.; Steele, E.M.; Millett, C.; Monteiro, C.A.; Levy, R.B. Ultra-Processed Food Consumption and Chronic Non-Communicable Diseases-Related Dietary Nutrient Profile in the UK (2008-2014) Nutrients. 2018, 10, 5, 587

2. WHO. Obesity and Overweight. Available online: https://www.who.int/fr/news-room/fact-sheets/detail/obesityand-overweight (accessed on 29 May 2021).

3. Yahfoufi, N.; Alsadi, N.; Jambi, M.; Matar, C. The Immunomodulatory and Anti-Inflammatory Role of Polyphenols. Nutrients. 2018, 10, 11, 1618.

4. Grotewold, E. The genetics and biochemistry of floral pigments. Ann. Rev. Plant Biol. 2006, 57, 761-780.

5. Benvenuti, S.; Bortolotti, E.; Maggini, R. Antioxidant power, anthocyanin content and organoleptic performance of edible flowers. Scientia Horticulturae, 2016, 199, 170-177

6. Horbowicz, M.; Kosson, R.; Grzesiuk, A.; Dębski, H. Anthocyanins of fruits and vegetables-their occurrence, analysis and role in human nutrition. Veget. Crops Res. Bull. 2008, 68, 5-22. 
7. Tian, J.; Chen, Mc.; Zhang, J.; Lee, K.; Song, T.; Zhang, H.; Yao, Y. Characteristics of dihydroflavonol 4-reductase gene promoters from different leaf colored Malus crabapple cultivars. Hortic Res, 2017, 4, 17070.

8. Vogt T. Phenylpropanoid biosynthesis. Mol Plant 2010, 3, 1, 2-20.

9. Ballistreri, G.; Fabroni, S.; Romeo, F., V.; Timpanaro, N.; Amenta, M.; Rapisarda, P.; Anthocyanins and Other Polyphenols in Citrus Genus: Biosynthesis, Chemical Profile, and Biological Activity. In Polyphenols in Plants, Watson, R.R.; Academic Press: London, United Kingdom, 2019, 191-2012.

10. Nelson D.L.; Cox M.; M. Lehninger, Principles of Biochemistry (3rd ed.). Worth Publishing. New York, USA, 2000; pp. 834-882

11. Montes-Ávila, J.; López-Angulo, G.; Delgado-Vargas, F. Tannins in Fruits and Vegetables: Chemistry and Biological Functions. In Fruit and Vegetable Phytochemicals: Chemistry and Human Health, ed. Yahia, E. Wiley-Blackwell; $2^{\text {nd }}$ edition Hoboken, New Jersey. 2017; 259-307

12. Carmona, L.; Alquézar, B.; Marques, V.V.; Peña, L. Anthocyanin biosynthesis and accumulation in blood oranges during postharvest storage at different low temperatures Food Chem., 2017, 237, 7-14,

13. Eidenberger, T., The Routine Analysis of Anthocyanins from Berries and Berry Products. In Occurrences, structure, Biosynthesis, and health Benefits based on their Evidences of medicinal Phytochemicals in Vegetables and fruits. ed. Motohashi N., Nova Science Publishers, Inc. New York, USA, 2013, 3, pp. 113-178

14. Mattioli, R.; Francioso, A.; Mosca, L.; Silva, P. Anthocyanins: A Comprehensive Review of Their Chemical Properties and Health Effects on Cardiovascular and Neurodegenerative Diseases. Molecules, 2020, 25, 3809

15. Clifford, M. N. Anthocyanins - nature, occurrence and dietary burden. J Sci Food Agric 2000, 80, $1063-72$.

16. Castañeda-Ovando, A.; de Lourdes Pacheco-Hernández, M.; Páez-Hernández, M.E.; Rodríguez, J.A.; Galán-Vidal, C.A. Chemical studies of anthocyanins: A review. Food Chem. 2009, 113, 859-871.

17. Burton-Freeman, B.; Sandhu, A.; Edirisinghe, I. Anthocyanins. In: Nutraceuticals: efficacy, safety and toxicity. ed. Gupta, R.C.; Academic, San Diego, USA, 2016, pp. 489-500.

18. Guo, H.; Xia, M. Anthocyanins and Diabetes Regulation. In Polyphenols in Human Health and Disease, 2014, vol. 1, Pages 83-93

19. Bakowska-Barczak A. Acylated anthocyanins as stable, natural food colorants-a review. Pol J Food Nutr Sci 2005; 14/55, pp. 107-16.

20. Miguel, M. G. Anthocyanins: Antioxidant and/or anti-inflammatory activities. J. Appl. Pharm. Sci. 2011, 01, 06, 07-15

21. Tena, N.; Martín, J.; Asuero, A.G. State of the Art of Anthocyanins: Antioxidant Activity, Sources, Bioavailability, and Therapeutic Effect in Human Health. Antioxidants 2020, 9, 451.

22. Tsuda, T.; Shiga, K.; Ohshima, K.; Kawakishi, S.; Osawa T. Inibhition of lipid peroxidation and the active oxygen radical scavengingeffect of anthocyanin pigments isolated from Phaseolus vulgaris L..Biochem. Pharmacol. 1996; 52, $1033-1039$.

23. García-Alonso, M.; Rimbach, G.; Rivas-Gonzalo, J.C.; De Pascual-Teresa, S. Antioxidant and cellular activities of anthocyanins and their corresponding vitisins A--studies in platelets, monocytes, and human endothelial cells. J Agric Food Chem. 2004, 2, 52, 11, 3378-84.

24. Harlen W.C., Jati, I.R.A.P. Antioxidant Activity of Anthocyanins in Common Legume Grains. In Polyphenols: Mechanisms of Action in Human Health and Disease 2nd ed.; Watson, R.R., Preedy, V.R., Zibadi, S. Eds., Publisher Academic Press, London, United Kingdom, 2018, Volume 1, pp. 87-99.

25. López-Alarcón, C.; \& Denicola, A. Evaluating the antioxidant capacity of natural products: A review on chemical and cellular-based assays. Analytica Chimica Acta, 2013, 763, 1-10.

26. Robles-Sanchez, M.; Gorinstein S.; Martin-Belloso, O.; Astiazaran-Garcia, H.; Gonzalez-Aguilar, G.A.; Cruz-Valenzuela, R. Minimal processing of tropical fruits: antioxidant potential and its impact on human health. Intersciencia, 2007, 32, 4, $227-232$.

27. Oliveira Filho, J. G. de; Braga, A. R. C.; Oliveira, B. R. de; Gomes, F. P.; Moreira, V. L.; Pereira, V. A. C.; Egea, M.B. The potential of anthocyanins in smart, active, and bioactive eco-friendly polymer-based films: A review. Food Research International, 2021, $142,110202$.

28. Kay, C.D.; Mazza, G.; Holub, B.J.; Anthocyanins exist in the circulation primarily as metabolites in adult men. J Nutr 2005, 135:2582-2588.

29. Nielsen, I.L.; Dragsted, L.O.; Ravn-Haren, G; Freese, R.; Rasmussen, S.E.; Absorption and excretion of black currant anthocyanins in humans and Watanabe heritable hyperlipidemic rabbits. J Agric Food Chem 2003, 51, 2813-2820

30. Mazza, G.; Kay, C. D.; Cottrell, T.; Holub, B. J. Absorption of anthocyanins from blueberries and serum antioxidant status in human subjects. J Agric Food Chem 2002, 50, 26, 7731-7737.

31. Matsumoto, H.; Inaba, H.; Kishi, M.; Tominaga, S.; Hirayama, M.; Tsuda, T. Orally administered delphinidin 3-rutinoside and cyanidin 3-rutinoside are directly absorbed in rats and humans and appear in the blood as the intact forms. J Agric Food Chem. 2001, 49, 3, 1546-51.

32. Bub, A.; Watzl, B.; Heeb, D.; Rechkemmer, G.; Briviba, K. Malvidin-3-glucoside bioavailability in humans after ingestion of red wine, dealcoholized red wine and red grape juice. Eur J Nutr. 2001, 40, 3, 113-20.

33. Nathan, C. Points of control in inflammation. Nature, 2002, 420 (6917), 846-852.

34. Janeway, C.A. Jr.; Medzhitov, R. Innate immune recognition. Annu. Rev. Immunol. 2002, 20, 197-216.

35. Hansson, G.K.; Libby, P.; Schonbeck, U.; Yan, Z.Q. Innate and adaptive immunity in the pathogenesis of atherosclerosis. Circulation Research. 2002, 91, 281-291.

36. Wright, S.D. Toll, a new piece in the puzzle of innate immunity. J Exp Med. 1999, 189, 605-609.

37. Takeda, K.; Akira, S. Toll-like receptors in innate immunity. Int. Immunol. 2005, 17:1-14. 
38. Forester, S.C.; Waterhouse, A.L. Gut metabolites of anthocyanins, gallic acid, 3-O-methylgallic acid, and 2,4,6-trihydroxybenzaldehyde, inhibit cell proliferation of Caco-2 cells. J Agric Food Chem. 2010 12, 58, 9, 5320-5327.

39. Kurimoto, Y., Shibayama, Y., Inoue, S., Soga, M.; Tikikawa, M; Ito, C.; Nanba, F.; Tsuda, T. Black soybean seed coat extract ameliorates hyperglycemia and insulin sensitivity via the activation of AMP-activated protein kinase in diabetic mice. J. Agric. Food Chem. 2013, 61, 23, 5558-5564.

40. Hardie, D. G. AMP-activated protein kinase: Maintaining energy homeostasis at the cellular and whole-body levels. Annual Review of Nutrition, 2014, 34, 1, 31-55.

41. Oak, M.H.; Bedoui, J.E.; Madeira, S.V., Chalupsky, K.; Schini-Kerth, V.B.; Delphinidin and cyanidin inhibit PDGF(AB)-induced VEGF release in vascular smooth muscle cells by preventing activation of p38 MAPK and JNK. Br. J. Pharmacol. 149, 2006, 3 , 283-290.

42. Wallace, T.C. Anthocyanins in cardiovascular disease. Adv Nutr. 2011, 2,1, 1-7.

43. Xia, M.; Ling, W.; Zhu, H.; Wang, Q.; Ma, J.; Hou, M.; Tang, Z.; Li, L.; Ye, Q. Anthocyanin prevents CD40-activated proinflammatory signaling in endothelial cells by regulating cholesterol distribution. Arterioscler Thromb Vasc Biol. 2007, 27, 3 , $519-24$

44. Fimognari, C.; Berti, F.; Nusse, M.; Cantelli-Forti, G.; Hrelia, P. Induction of apoptosis in two human leukemia cell lines as well as differentiation in human promyelocytic cells by cyanidin-3-O-beta-glucopyranoside. Biochem Pharmacol 2004, 67: 2047-2056

45. Jayaprakasam, B.; Vareed, S.K.; Olson, L.K.; Nair, M.G. Insulin secretion by bioactive anthocyanins and anthocyanidins present in fruits. J Agric Food Chem. 2005 , 12, 53, 1, 28-31.

46. Wang, C.J.; Wang, J.M.; Lin, W.L.; Chu, C.Y.; Chou, F.P.; Tseng, T.H. Protective effect of Hibiscus anthocyanins against tert-butyl hydroperoxide-induced hepatic toxicity in rats. Food Chem Toxicol. 2000, 38, 5, 411-6

47. Galvano, F.; La Fauci, L.; Lazzarino, G.; Fogliano. V.; Ritieni, A.; Ciappellano, S.; Battistini, N.C.; Tavazzi, B.; Galvano, G. Cyanidins: metabolism and biological properties. J Nutr Biochem. 2004, 15,1, 2-11.

48. Werlein, H.-D.; Kütemeyer, C.; Schatton, G.; Hubbermann, E. M.; Schwarz, K. (2005). Influence of elderberry and blackcurrant concentrates on the growth of microorganisms. Food Control, 2005, 16, 8, 729-733

49. Knox, Y.M.; Suzutani, T.; Yosida, I.; Azuma, M. Anti-influenza virus activity of crude extract of Ribes nigrum L. Phytother Res. 2003, 17, 2, 120-2.

50. Joseph, J.A.; Shukitt-Hale, B.; Denisova, N.A.; Bielinski, D.; Martin, A.; McEwen, J.J.; Bickford, P.C. Reversals of age-related declines in neuronal signal transduction, cognitive, and motor behavioral deficits with blueberry, spinach, or strawberry dietary supplementation. J Neurosci. 1999, 15, 19, 18, 8114-21.

51. Joseph, J.A.; Denisova, N.A.; Arendash, G.; Gordon, M.; Diamond, D.; Shukitt-Hale, B.; Morgan, D. Blueberry supplementation enhances signaling and prevents behavioral deficits in an Alzheimer disease model. Nutr Neurosci. 2003, 6, 3, $153-62$.

52. Samarpita, S.; Rasool, M. Cyanidin attenuates IL-17A cytokine signaling mediated monocyte migration and differentiation into mature osteoclasts in rheumatoid arthritis. Cytokine, 2021, 142, 155502.

53. Maya-Cano, D. A.; Arango-Varela, S.; Santa-Gonzalez, G. A. Phenolic compounds of blueberries (Vaccinium spp) as a protective strategy against skin cell damage induced by ROS: A review of antioxidant potential and antiproliferative capacity. Heliyon, 2021, 7, 2, e06297

54. Spinardi, A.; Cola, G.; Gardana, C.S.; Mignani, I. Variation of anthocyanin content and profile throughout fruit development and ripening of highbush blueberry cultivars grown at two different altitudes. Front. Plant Sci. 2019, $10,1045$.

55. Passeri, V., Koes, R., and Quattrocchio, F. M. New challenges for the design of high value plant products: stabilization of anthocyanins in plant vacuoles. Front. Plant Sci. 2016, 7, 153.

56. Katsumoto, Y.; Fukuchi-Mizutani, M.; Fukui, Y.; Brugliera, F.; Holton, T.A.; Karan, M.; Nakamura, N. Engineering of the rose flavonoid biosynthetic pathway successfully generated blue-hued flowers accumulating delphinidin. Plant Cell Physiol. 2007 $48,1589-1600$.

57. Liu, C.-H.; Liu, Y. Fruit quality and differentially expressed genes of winter-harvested pineapple in response to elevated temperature over a short postharvest period. Postharvest Biol Technol, 2017, 130, 21-27.

58. Ban, T., Ishimaru, M., Kobayashi, S., Shiozaki, S., Goto-Yamamoto, N., Horiuchi, S. Abscisic acid and 2,4-dichlorophenoxyacetic acid affect the expression of anthocyanin biosynthetic pathway genes in 'Kyoho' grape berries. J. Hortic. Sci. Biotechnol. 2003, 78, 586-589.

59. Xi, X.; Zha, Q.; Jiang, A.; Tian, Y. Impact of cluster thinning on transcriptional regulation of anthocyanin biosynthesis-related genes in 'summer black' grapes. Plant Physiol. Biochem. 2016, 104, 180-187.

60. Cobbina, J.; Miller, M. H. Purpling in Maize Hybrids as Influenced by Temperature and Soil Phosphorus1. J. Agron., 1987, 79, 3 , 576.

61. Arnao, M.B.; Hernández-Ruiz, J. Melatonin in its relationship to plant hormones. Ann. Bot., 2018, 121, $195-207$.

62. Hu, J.; Fang, H., Wang, J.; Yue, X.; Su, M.; Mao, Z.; Chen, X. Ultraviolet B-induced MdWRKY72 expression promotes anthocyanin synthesis in apple. Plant Science, 2020, 292, 110377.

63. Davies, K.M.; Schwinn, K.E. Deroles, S.C.; Manson, D.G.; Lewis, D.H.; Bloor, S.J.; Bradley, J.M. Enhancing anthocyanin production by altering competition for substrate between flavonol synthase and dihydroflavonol 4-reductase. Euphytica, 2003, 131:259-268

64. de Pascual-Teresa S, Sanchez-Ballesta MT. Anthocyanins: from plant to health. Phytochem Rev 2007, 7, 2, 281_99.

65. Weiss, D.; van Blokland, R.; Kooter, J. M.; Mol, J. N. M.; van Tunen, A.J. Gibberellic Acid Regulates Chalcone Synthase Gene Transcription in the Corolla of Petunia hybrida Plant Physiol. 1992, 98, 191-197 
66. Ben-Nissan, G.; Weiss, D. The petunia homologue of tomato gast1: transcript accumulation coincides with gibberellin-induced corolla cell elongation. Plant Mol Biol. 1996 32, 6, 1067-74.

67. Chirol, N.; Jay, M. Acylated anthocyanins from flowers of Begonia. Phytochemistry, 1995, 40 ,1, 275-277

68. De Morais, J.S.; Sant'Ana, A.S.; Dantas, A.M.; Silva, B.S.; Lima, M.S.; Borges, G.C.; Magnani, M. Antioxidant activity and bioaccessibility of phenolic compounds in white, red, blue, purple, yellow and orange edible flowers through a simulated intestinal barrier. Food Res. Int. 2020, 131, 109046.

69. Saito, N.; Toki, K.; Honda, T.; Kawase, K. Cyanidin 3-malonylglucuronylglucoside in Bellis and cyanidin 3-malonylglucoside in Dendranthema Phytochemistry. 1988, 27, 9, 2963 - 2966

70. Brandt, K., Kondo, K., Aoki, H., Goto, T. Structure and biosynthesis of anthocyanins in flowers of Campanula. Phytochemistry. 1993, 33, 1, 209-212

71. Chen, G.L.; Chen, S.G.; Xie, Y.Q.; Chen, F., Zhao, Y.; Y., Luo, C.X.; Gao, Y.Q. Total phenolic, flavonoid and antioxidant activity of 23 edible flowers subjected to in vitro digestion. J. Funct. Foods, 2015, 17, 243-259.

72. Asen, S., Stewart, R. N., Norris, K.H., Pelargonidin 3-di (p-hydroxybenzoyl) rutinoside-7-glucoside from flowers of Campanula. Phytochemistry, 1979, 18, 1251-1252.

73. Janarny, G,; Ranaweera, K.K.D.S.; Gunathilake, K.D.P.P. Antioxidant activities of hydro-methanolic extracts of Sri Lankan edible flowers Biocatal. Agric. Biotechnol., 2021, 35, 102081,

74. Lara-Cortes, E.; Martin-Belloso, O.; Osorio-Diaz, P.; Barrera-Necha, L.L.; Sanchez-Lopez, J.A.; Bautista-Banos, S. Actividad antioxidante, composicion nutrimental y funcional de flores comestibles de dalia. Rev. Chapingo Ser. Hortic. 2014, 20, 101-116.

75. Pires, T. C. S. P.; Dias, M. I.; Barros, L.; Barreira, J. C. M.; Santos-Buelga, C.; Ferreira, I. C. F. R. Incorporation of natural colorants obtained from edible flowers in yogurts. LWT - Food Sci Technol, 2018, 97, 668-675.

76. Abe, Y.; Tera, M.; Sasaki, N.; Okamura, M.; Umemoto, N.; Momose, M.; Kawahara, N.; Kamakura, H.; Goda, Y.; Nagasawa, K.; Ozeki, Y.; Detection of 1-O-malylglucose: Pelargonidin 3-O-glucose-6"-O-malyltransferase activity in carnation (Dianthus caryophyllus), Biochem. Biophys. Res. Commun. 2008, 373, 4, 473-477

77. Li, D., Wang, P., Luo, Y., Zhao, M., \& Chen, F. Health benefits of anthocyanins and molecular mechanisms: Update from recent decade. Crit Rev Food Sci Nutr. 2015, 57, 8, 1729-1741.

78. Suzuki, H.; Nakayama, T.; Yamaguchi, M.; Nishino, T. cDNA cloning and characterization of two Dendranthema $\times$ morifolium anthocyanin malonyltransferases with different functional activities. Plant Science 2004, 166, 89-96

79. Chen, G-L.; Chen, S.; Xiao, Y.; Fu, N. Antioxidant capacities and total phenolic contents of 30 flowers. Industrial Crops and Products, 2018, 111, 430-445

80. Crowden, R. K.; Wright J.; Harborne, J. B. Anthocyanins of Fuchsia (onagraceae) Isorhamnetin 3,7-disulphate from flaveria bidentis Phytochemistry. 1977, 16, 40

81. Saito, N.; Harborne, J.B. Correlations between anthocyanin type, pollinator and flower colour in the labiatae. Phytochemistry. 1992, 31,9, 3009-3015

82. Zengin, G.; Cvetanović, A.; Gašić, U.; Tešić, Ž.; Stupar, A.; Bulut, G.; Sinan, C.I.; Picot-Allain, M.C.N.; Mahomoodally, M.F., A comparative exploration of the phytochemical profiles and bio-pharmaceutical potential of Helichrysum stoechas subsp. barrelieri extracts obtained via five extraction techniques, Process Biochemistry 2020, 91, 113-125.

83. Kao, F. J.; Chiang, W. D.; Liu, H.M. Inhibitory effect of daylily buds at various stages of maturity on nitric oxide production and the involved phenolic compounds. LWT - Food Sci Technol, 2015, 61, 1, 130-137.

84. Fernandes, L.; Casal, S.; Pereira, J. A.; Saraiva, J. A.; Ramalhosa, E. Edible flowers: A review of the nutritional, antioxidant, antimicrobial properties and effects on human health. J. Food Compos. Anal., 2017, 60, 38-50

85. Grajeda-Iglesias, C.; Figueroa-Espinoza, M. C.; Barouh, N.; Baréa, B.; Fernandes, A.; de Freitas, V.; Salas, E. Isolation and Characterization of Anthocyanins from Hibiscus sabdariffa Flowers. J. Nat. Prod., 2016, 79(7), 1709-1718.

86. Nakamura, Y.; Hidaka, M.; Masakia, H.; Seto, H.; Uozumi. T. Major anthocyanin of the flowers of hibiscus (Hibiscus rosa-sinensis L.) Agric. Biol. Chem., 1990, 54 (12) 3345-3346

87. Lu, B.; Li, M.; Yin, R. Phytochemical Content, Health Benefits, and Toxicology of Common Edible Flowers: A Review (2000-2015). Crit. Rev. Food Sci. Nutr., 2015, 56(sup1), S130-S148.

88. Klozová, E.; Rokosavá, K. Anthocyanins of Impatiens holstii., Biol. Plantarum 1961, 3, 291-296.

89. Tatsuzawa, F.; Usuki, R.; Toki, K.; Saito, N.; Shinoda, K.; Shigihara, A.; Honda T. Acylated pelargonidin 3-samububioside-5-glucosides from the red-purple flowers of Lobularia maritima J. Jpn. Soc. Hortc. Sci., 2010, 79, 84-90

90. Tatsuzawa, F.; Toki, K.; Saito, N.; Shinoda, K.; Shigihara, A.; Honda T. Four acylated cyanidin 3-sambubioside-5-glucosides from the purple-violet flowers of Lobularia maritima Heterocycles, 2007, 71, 1117-1125

91. Mitchell, K.A.; Markham, K.R.; Boase, M.R. Pigment chemistry and colour of Pelargonium flowers Phytochemistry, 1998, 47 (3) 355-361

92. Griesbach, R. J.; Asen, S.; Leonnarat, B. A. Petunia hybrida anthocyanins acylated with caffeic acid. Phytochemistry, 1991, 30,5, 1729-1731.

93. Berardi, A.E.; Esfeld, K.; Jäggi, L.; Mandel, T.; Cannarozzi, G.M.; Kuhlemeier, C. Complex evolution of novel red floral color in Petunia, The Plant Cell, 2021, 33, 7, 2273-2295,

94. Lee, J.H., Lee, H-J, Choung, M-G., Anthocyanin compositions and biological activities from the red petals of Korean edible rose (Rosa hybrida cv. Noblered), Food Chemistry, 2011, 129(2) 272-278,

95. Cendrowski, A., 'Scibisz, I., Mitek, M., Kieliszek, M., Kolniak-Ostek, J. Profile of the phenolic compounds of Rosa rugosa petals. J. Food Qual., 2017, ID 7941347, 
96. Friedman, O.; Agami, Y.; Vinokur, S.; Droby, L.; Cohen, G.; Refaeli, N.; Resnick, N.; Umiel, N. Characterization of yield: sensitivity to Botrytis cinerea and antioxidant content of several rose species suitable for edible flowers Sci. Hort., 2010, 123:395-401

97. Navarro-González, I.; González-Barrio, R.; García-Valverde, V.; Bautista-Ortín, A.B.; Periago, M.J. Nutritional Composition and Antioxidant Capacity in Edible Flowers: Characterisation of Phenolic Compounds by HPLC-DAD-ESI/MS ${ }^{\mathrm{n}}$. Int. J. Mol. Sci. 2015, 16, 805-822.

98. Deineka, V.; Kulchenko, Y.; Blinova, I.; Deineka, L.; Chulkov A. Anthocyanins of Tagetes patula flower petals. Res. J. Pharm. Biol. Chem. Sci. 2016, 7, 5, $2986-2993$

99. Fukuzaki, E.; Kawasaki, K., Kajiyama, S., An, C., Suzuki, K., Tanaka, Y., Kobayashi, A. Flower color modifications of Torenia hybrida by down-regulation of chalcone synthase genes with RNA interference. J Biotechnol 2004, 111, 229-240

100. Suzuki K, Xue H, Tanaka Y, Fukui Y, Fukuchi-Muzutani M, Murakami Y, Katsumoto Y, Tsuda S, Kusumi T Flower color modifications of Torenia hybrida by co-suppression of anthocyanin biosynthesis genes. Mol. Breed. 2000, 6, 239- 246

101. Garzón, A.G.; Manns, D.C.; Riedl, K.; Schwartz, S.J.; Padilla-Zakour, O. Identification of Phenolic Compounds in Petals of Nasturtium Flowers (Tropaeolum majus) by High-Performance Liquid Chromtography Coupled to Mass Spectrometry and Determination of Oxygen Radical Absorbance Capacity (ORAC) J. Agric. Food Chem. 2015, 18, 63, 6, $1803-11$.

102. Nakayama, M.; Okada, M.; Taya-kizu, M.; Urashima, O.; Kan, Y.; Fukui, Y.; Koshioka, M. 2004. Coloration and Anthocyanin Profile in Tulip Flowers. Jpn. Agric. Res. Q., 2004, 38, 3, 185-190.

103. Yuan, Y.; Ma, X.; Tang, D.; Shi, Y. Comparison of anthocyanin components, expression of anthocyanin biosynthetic structural genes, and TfF3'H1 sequences between Tulipa fosteriana "Albert heijn" and its reddish sport. Sci. Hort., 2014, 175, 16-26

104. Fawzi Mahomoodally, M., Zengin, G., Ibrahime Sinan, K., Yıldıztugay, E., Lobine, D., Ouelbani, R., Bensari, S.; Yilmaz, M.A.; Montesano, D. A comprehensive evaluation of the chemical profiles and biological properties of six geophytes from Turkey: Sources of bioactive compounds for novel nutraceuticals. Food Res. Int., 2021, 140, 110068.

105. Krzymińska, A.; Gąsecka, M.; Magdziak, Z. Content of Phenolic Compounds and Organic Acids in the Flowers of Selected Tulipa gesneriana Cultivars. Molecules 2020, 25, 5627.

106. Moliner, C.; Barros, L.; Dias, M. I.; Reigada, I.; Ferreira, I. C. F. R.; López, V., Langa, E.; Rincón, C. G. Viola cornuta and Viola x wittrockiana: Phenolic compounds, antioxidant and neuroprotective activities on Caenorhabditis elegans. J Food Drug Anal. 2019, 27, 849-859

107. González-Barrio, R.; Periago, M. J.; Luna-Recio, C.; Garcia-Alonso, F. J.; Navarro-González, I. Chemical composition of the edible flowers, pansy ( Viola wittrockiana) and snapdragon ( Antirrhinum majus ) as new sources of bioactive compounds. Food Chem., 2018, 252, 373-380.

108. Skowyra, M.; Calvo, M. I.; Gallego, M. G.; Azman, N. A. M.; Almajano, M. P. Characterization of Phytochemicals in Petals of Different Colours From Viola $\times$ wittrockiana Gams. and Their Correlation With Antioxidant Activity. J. Agric. Sci., 2014, 6, 9

109. Torskangerpoll, K., Nørbæk, R.; Nodland, E.; Øvstedal, D. O.; Andersen, Ø. M. Anthocyanin content of Tulipa species and cultivars and its impact on tepal colours. Biochem. Syst. Ecol. 2005, 33, 5, 499-510.

110. Yuan, Y., Ma, X., Tang, D., Shi, Y. (2014). Comparison of anthocyanin components, expression of anthocyanin biosynthetic structural genes, and TfF3'H1 sequences between Tulipa fosteriana "Albert heijn" and its reddish sport. Scientia Hort., 2014, $175,16-26$.

111. Lovell, S., Johnston D. Designing Landscapes for Performance Based on Emerging Principles in Landscape Ecology. Ecology and Society 2009, 14,4, 44 .

112. Palmer, I. The balcony gardener : creative ideas for small spaces. Ryland Peters \& Small; CICO Books. London. Great Britain

113. Rivas-Gonzalo, J.C. Analysis of Anthocyanins. In: Methods in polyphenol analysis. Eds. Santos-Buelga C.; Williamson, G. The Royal Society of Chemistry, Cambridge 2003, 287

114. Ayala-Zavala, J.F.; Wang, S.Y.; González Aguilar, G.A. High Oxygen Treatment Increases Antioxidant Capacity and Postharvest Life of Strawberry Fruit. Food Technol. Biotechnol. 2007, 45, 2, 2

115. Leja, M.; Mareczek, A.; Ben, J. Antioxidant properties of two apple cultivars during long-term storage. Food Chem 2003, 80, 3 , 303-307. 